\title{
Based on The Research and Application of Tengen Software in Architectural Design Teaching Process
}

\author{
TANG Hong ${ }^{\text {a }}$, FAN Guo-ling ${ }^{\text {b }}$
}

Department of Urban Planning and Archchitecture, Henan University of Urban Construction, Pingdingshan, Henan, China 467000

\begin{abstract}
With the continuous development of high technology, architectural design is on the way to paperless digital era. In order to help students grasp and skillfully apply the architectural computer aided design software and cultivate talented architects with the times, this article is going to bring the Tangent software into architectural teaching. On the basis of graphic and elevation design, section design, three-dimensional modeling and so on in architecture, It expounded the early program draft and the control of late deepening program in view of Tangent software, pointing out the interaction between design software and architectural program so as to make students really understand the function of Tangent software and then improve the students' comprehensive skills.
\end{abstract}

Index Terms: Tengen software; architectural teaching; architectural design; control; function

(C) 2011 Published by MECS Publisher. Selection and/or peer review under responsibility of the International Conference on E-Business System and Education Technology

\section{Introduction}

Nicholas Negroponte once said: Bit, DHA as information is rapidly replacing atom as the basic elements of human society. Nowadays it has become a reality, digital and information communication has penetrated into various fields., questionnaire survey about 32 design units In Beijing found that two-dimensional drawings has achieved $100 \%$ computerization,,industry standards are generally formed ${ }^{[1]}$. In the architectural design field , The application of computer graphics and Plotting has become an unwritten rule, which Tengen architectural design software is so far the most widely used In the architectural design field.so that Architectural teaching must adapt to the evolution of times and subject to development, in order to cultivate the real talent in line with the age, we introduce Tengen building software to basic teaching of architectural design .

* Corresponding author.

E-mail address: ${ }^{\mathrm{a}}$ Tanghong969@126.com, ${ }^{\mathrm{b}}$ artjust@163.com 


\section{The Problems Encountered in The Teaching Process}

From the present situation, the two-dimensional drawing software are far from perfect. The contradiction of computer limit people still exist .This contradiction is mainly embodied in computer-aided design software on the the control of early draft program and late deepening programs.

\section{A. Architectural design aided software Control thinking}

Designers direct expression of thinking rely on sketches.Draft is a multi-defined graphic, whe $\mathrm{n}$ different or the same viewer watch in different methods can arose various imaginations. The potential content it expresses is far more than the line graph. That means sketch is fuzzy and ambiguity.Usually a designer careless about the internal structure of the graphics tools he uses, designers are most concerned about the in-depth design represent by the graph.But the computer graphics are different, to a large extent it (for designers) is the precise structure of their own which is useful.It is independent comparing Itself with the object to be described. As Steny said: "Ambiguity brings inspiration, inspire creativity, promote the multi-level expression and feedback, and thus it is important for the design. It is clear that,when a computer-aided design is completed,ambiguity does not exist; even when the graphics on the computer is in the most simple line graph and so do,... "[2] Thus, the accuracy of computer-aided design and ambiguity of sketch design is undoubtedly contradictory .Therefore, we must emphasize sketch combined with computer-aided design software.

\section{B. Architectural design aided software Control expression}

Drawing software has dramatically increased the gap between different degrees of difficulty of architectural graphics design, in this way designers is more willing to design into some shape in the process of expression.,to be able to to use the building design software to draw out quickly ${ }^{[3]}$. This phenomenon is known as software "fit in between.'It resulted to the loss of architectural creation during the architectural creation, it is mutually contradictory that architectural design stressed the spirit of innovation.

\section{Tengen software applying in architecture education}

\section{A. Tengen building software combinate with hand-drawn sketches}

Architectural designs are starting from sketche. A beautiful sketch Includes what the architect is most proud of: inspiration and creativity.sketch design is the most critical steps in materializing draft, without it, don't talk about design. However, in the real process of teaching, we found that the combination lies mainly in two aspects: on the one hand, the students early involved the computer in the design process. on the other hand, the students out of line with the draft when they use Tengen software programs. Therefore, in practical teaching, we limited time for involved mapping software to design. In the prophase, the program's basic problem is almost solved, this time may intervene Tengen architectural design software to draw.Regard to expressing the program out of line with the sketch, we will scan the architectural design sketches, make full use of the advantages of Tengen Architectural software, using 【insert】--【raster image 】 to be creatively quide draft into the software, then use the software to scan down the draft, so the advantage of the draft will be saved, and ultimately achieved the combination of Tengen architectural software and draft. (Figure 1) 


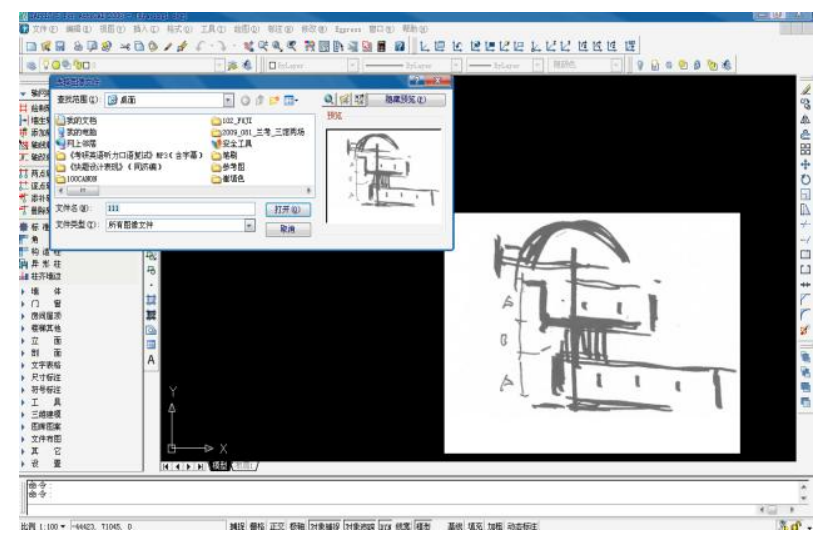

Figure 1. Tengen architectural design software combination with sketch.

\section{B. The power of the Tengen software}

"Gentleman's nature are no different to most people, but they are good at borrowing the strength of other objects." ${ }^{[4]}$ people only focus on the control of technology can they give full play to the benefits of technology, the computer's role in the architect can play efficiently and completely.However, in reality the designer for the architectural design software has a certain fitness, objectively speaking, responsible for the concequnces is not from the software developers but users - software users who's lazy and do not understand the function of the software itself.In the real teaching process, most students only knew one aspect of Tengen learning software, but don't know the other; paradoxical and ambiguous.Students always satisfied when they can draw one picture,and the teachers measure student' achievement by whether they can draw a complete picture at last.This kind of way lack supervision to the students whether they really grasp the software or not .The inevitable result of the drawing software to students is mapping software slaves, so we must pay more attention to comprehensive features of architectural design assistant softwareThereinto, Tengen CAD series software has been so popularized In architechtural design industry, for its convenience, shortcut and easily changing.

\section{1) Graphic Design}

The graphic design starts from the axis, the wall line is fundamental. [drawing grids] in the 【Column grids 】 command can easily draw a straight line and HXZW, together with the add 、 move、 trim etc editing tools, this way ensure the designer complete any layout .(Figure 2)[Axis create walls] in the【wall】 .can be directly generated double line wall along the

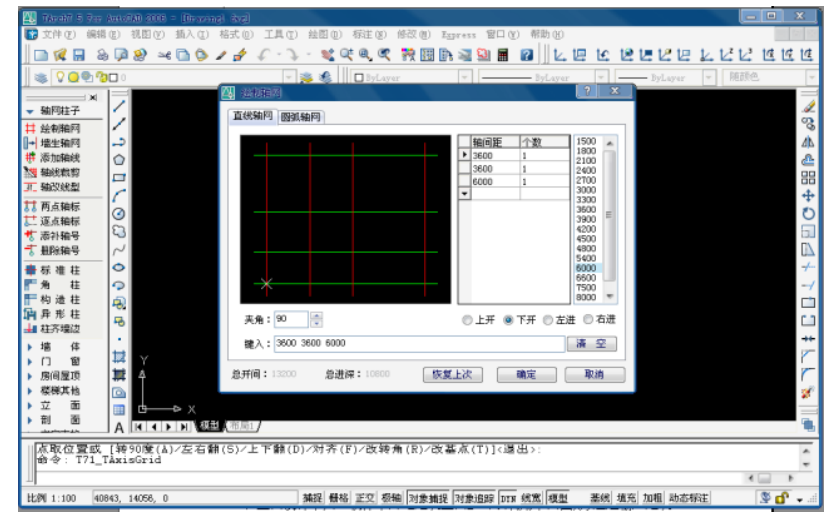

Figure 2. the positioning of the axis in the graphic design 
axis, the user can edit the wall furtherly, such as trim, plus or cut, copy, move and so on. [windows] in the 【Window】 command as well, fir`t of all doors and windows are free to edit the size, and secondly, you can pen doors and windows of different size and orientation on the line of the wall directly according to the needs.In addition, a large range of options for doors and windows.both rich in design and accurately express design intent.For example: sliding doors, doors with slid windows, side-hung windows、Pingkaimen window, can be freely chosen according to your needs.In the design process, the exchange of doors and windows, its type exchange and replacement, as well as the direction of its opening, the size of the change, may change at any time on command, which has brought great convenience to the designers .[general gallery]in the 【Pattern gallery】 used generally in the program design. Gallery is divided into two parts, systems and users, system gallery is the common gallery tengen software providing to the users, the self-built and the collection gallery are the important accumulated information .Make use of the furniture in the Gallery can achieve the layout of interior space, so the drawing is more popular, Not only for the non-professionals understand the design more conveinetly, but also for designers easy to check the rationality of the space design. Insertion of the flat surface, enriching the surface, increasing the sense of beauty, while making the design humminity ${ }^{[5]}$.

\section{2) Elevation design}

In elevation design, 【building elevation】 in the Tangent software design pane can be used by entering the building floors, through input the building storey height difference of elevation between inside and outside 、 window height and other parameters directly generated elevation (Figure 3).And then use the drawing tools to complement and enrich the elevation.The【roof elevation】 use parameter dialog box, the users can choose in any of 10 selected several roofing needs. 【Elevation contours 】 can automatically search the outline of the building, for a short time, just simply enter the width can be automatically generated.【elevation windows \ can be directly inserted, but also can draw their own editing block to use at any time. Even if the size of the generated windows and height can be changed by changing the size of its parameters.

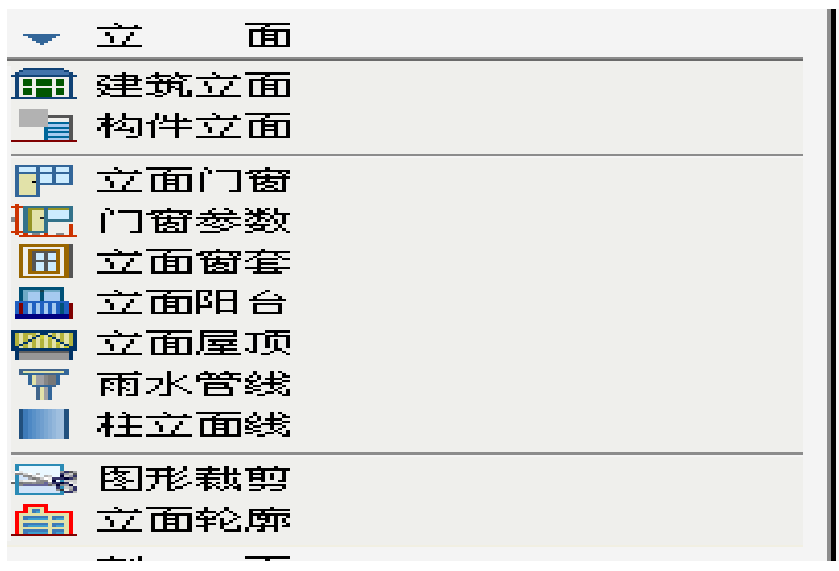

Figure 3. rich elevation menu

\section{3) Section design}

In elevation design, 【building section】 in the Tangent software design pane can be used by entering the building floors, plane figure can still be used to set the section position, the input the building storey height, difference of elevation between inside and window height and height parameters directly generated sections. Also can use section command to further draw the section. Such as: drawing section walls, double line floors, precast floors slab, plus split-off beams, doors and windows sections, section eaves and other commands, you can simply draw out use software. Cutting the parts and visible part of the graph section can be distinguished after, 
so the designer used by glance. Stairs section in the section design of is often difficult to draw. but use tangent software is very easy: one is directly through the plan to generate, can be slightly modified into a drawing; the other is through the 【parameters of the stairs】 direct draw, simply enter the stepping height, width, step number and rest platform width, can be generated, and in the drawing section and can be seen directly distinguish between section and visible section (Figure 4).

4) Dimension

[Dimension] is a complex and important parts of drawing. Tangent provides tools for users to consider the dimension very thoughtful, doors and windows mark, thickness of the wall

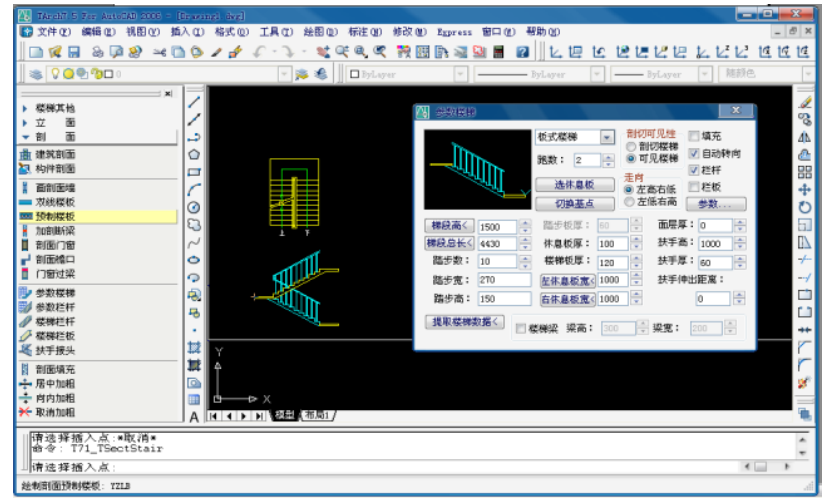

Figure 4. generated the section shortcut

mark, by point market, radius dimension, angle dimension and arc length dimension. And provides modify tool of size editing 、 size self-adjusting so easily. Users can not only facilitate the conduct of all marked, but also can cancel、connection、 break, plus or cut or even modify the size ; combined, divide and so on.

5) Three-dimensional modeling

Tangent software is still a good tool for modeling, and also configured in the Tangent powerful rendering capabilities. Designers can directly generate three-dimensional model from floor plan, so this can let students to make up for the early learning in the lack of spatial cognition ${ }^{[6]}$.Besides, in the late-processing can also use doors and windows, walls, staircases, roofs and other 3D editing and modeling tools for complete. The model also can import 3DS MAX rendering, Completed the ultimate expression of the results.(Figure 5).

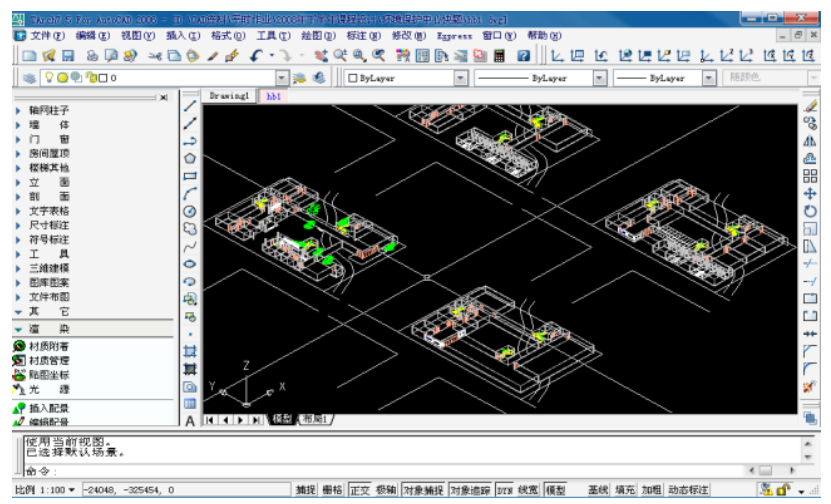

Figure 5. the powerful three-dimensional modeling function 
6) Mark Tools

Tangent software also contains a variety of intelligent special building symbols. Including the elevation mark, the arrow cited note, index drawing name, section cutting, section, plus broken line, drawing compass, name mark, etc. These tools are in line with the relevant national standards and architects drawing habits then greatly improve the architects using efficiency ${ }^{[7]}$.Tangent software also has many other functions, such sunshine analysis. Can calculated directly between the two buildings blocking sunlight, and can calculate the structure of sunshine in the winter solstice time. only if we familiar with its function we can get rid of the greatest degree of "adaptability", the better let the software service for us ${ }^{[8]}$.

\section{Conclusion}

With the deepening of information technology, architectural design is moving toward a paperless digital age

${ }^{[9]}$.In order to realize computer-aided design, we not only have to correctly understand the Tangent architectural design software relationship with traditional drawing methods, but also good grasp powerful function of Tangent architectural design software. This requires that to the future teaching we must pay more attention to concepts thinking and software functions comprehensive, thus greatly improving the efficiency of teaching architecture [10]

\section{References}

[1] Zhang Lei. Digital technology used to explore basic teaching of architectural design [J]. Huazhong Architecture 2010 (2) :194-195 (In Chinese).

[2] Zhang Li. From CAAD to Cyberspace (Information Age architecture and architectural design) [M]. Nanjing: Southeast University Press .2002:96-98 (In Chinese).

[3] Li Zuofeng. Xun zi [M]. Beijing: Higher Education Press .2008:6(In Chinese).

[4] Xue Hang. Computer-aided design in architectural design [J]. Shanxi Radio \& TV University Journal 2005 (7) :81-82(In Chinese).

[5] BARBOSACAM, DREUXM, BENTOJ, teal. An object model for collaborative CAD environments[A].The 7th International conference on Computer Supported Cooperative Work in Design. NRC Research Press,2002:179-184.

[6] Qu Jianmin. Multimedia Technology and Applications Tutorial [M]. Beijing: Tsinghua University Press .2005,4:24-25(In Chinese).

[7] Mark Laden. The Architects Guide to Computer Aided Design[M].ACM Press.2004:24

[8] Li Jiancheng. Digital Architecture Design Introduction [M]. Beijing: China Building Industry Press .2007.62(In Chinese).

[9] You Fu. Building information model to bring design thinking and methods of transformation [J]. Building of 2009 (1):77-80(In Chinese).

[10] Xu Weiguo. Digital Construction [J]. Architectural Journal, 2009 (1) :61-63(In Chinese). 